\title{
Rethink Your Public Space: Community Events in Gentrified Brooklyn
}

\author{
Sara Martucci*
}

CUNY Graduate Center, 365 Fifth Avenue, New York, NY 10016, USA

\begin{abstract}
Retail and demographic gentrification is well documented in the social sciences, but few studies have examined the impact of this process on a neighborhood's public spaces. This paper focuses on an annual street closure event in Williamsburg, Brooklyn -a former working class neighborhood that is now attracting wealthy members of the upper class. 'Williamsburg Walks,' part of a New York City initiative, eliminates car traffic on the main commercial street for select summer weekends. Residents and visitors are encouraged to 'rethink' their use of the street during the closure. However merchants, residents, and event organizers each have different motives and expectations for 'Williamsburg Walks.' While the event aims to create more public space and 'a celebration of neighborhood,' it also serves an implicit goal of branding the neighborhood for the wealthy at the exclusion of long-term residents. I analyze 'Williamsburg Walks' in terms of a branding strategy using ethnographic data from the 2008-2010 events.
\end{abstract}

Keywords: Branding, Brooklyn, gentrification, neighborhood studies, public space.

\section{INTRODUCTION}

The process of deindustrialization has significantly altered many American urban centers. For some former manufacturing neighborhoods, a real change of image was necessary for a successful shift from a production to service economy. This has certainly been the case for Williamsburg, Brooklyn, which has experienced dramatic demographic changes in the social and economic makeup of the neighborhood. Through the combined efforts of public policy, real estate developers, and retail entrepreneurs, Williamsburg is dangerously close to being an upper class enclave [1]. The case of retail and residential gentrification in Williamsburg has already been studied by several scholars [2-4]. I intend to fill a gap in this literature by studying how uses of public space reflect the tensions and goals of a gentrifying neighborhood.

Although many long-term residents still live in the neighborhood, the public spaces and institutions of Williamsburg have changed to meet the cultural and economic capital of newcomers [5]. In the past decade there has been a boon in the development of community events in the neighborhood's public spaces, which attract visitors and new residents to Williamsburg. These events range from movie, music and culinary festivals to luxury condo sponsored 'family fun days'; and they help to brand Williamsburg as a destination of leisure and culture [6]. But how do new events impact the lives of long-term residents and their use of the neighborhood's public spaces?

This paper examines the inception and development of one such event, 'Williamsburg Walks' over the course of three summers, 2008-2010. Williamsburg Walks was a

*Address correspondence to this author at the CUNY Graduate Center, 365 Fifth Avenue, New York, NY 10016, USA; Tel: 631-766-6904; E-mail: sara.martucci@gmail.com forerunner of 'Summer Streets', a public space 'experiment' which entails closing the street to car traffic and encouraging individuals to use the space as they wish. The 'Summer Streets' program is managed by the city's Department of Transportation $(\mathrm{DOT})^{2}$, which deals with issues of space and traffic safety relating to the city's motorists, cyclists and pedestrians.

Despite the emphasis on public space and interaction, 'Walks' is one of many community events in Williamsburg that result in the exclusion of long-time residents. I argue that this event can be viewed as a strategy in the branding of Williamsburg as a luxurious and upscale community. Because Williamsburg Walks is part of a broader initiative proposed by DOT and the City of New York, it is important to understand how these events are planned and what effects they might have on diverse neighborhoods. This paper focuses on a case study of 'Williamsburg Walks,' a street closure event on Bedford Avenue, the main retail and transportation street of North Williamsburg.

In this paper I first situate Williamsburg as representative of many Western post-industrial neighborhoods, although this is a case study it is applicable to other gentrified locales beyond Brooklyn, New York, and the United States. I then review the literature on public space and exclusion in the context of gentrification. Using Williamsburg Walks as a case study of community events in gentrified neighborhoods, I give a thorough description of the event using Internet data, end-reports by planners, interviews with organizers and participants, and ethnographic observations from planning meetings and the event itself. Finally, I analyze the role of Williamsburg Walks in terms of branding the neighborhood.

\section{WILLIAMSBURG, BROOKLYN}

Located on the North West tip of Brooklyn that juts out into New York's East River, Williamsburg was an ideal

\footnotetext{
${ }^{1}$ http://www.nyc.gov/html/dot/summerstreets/html/home/home.shtml ${ }^{2}$ http://www.nyc.gov/html/dot/html/about/about.shtml
} 
location for manufacturing in the late nineteenth and twentieth centuries [3]. The surplus of factory jobs attracted immigrants, predominantly from Italy and Eastern Europe, to the neighborhood's 'Northside'. Williamsburg remained solidly working class throughout the $1980 \mathrm{~s}$ when manufacturing companies began moving out of the neighborhood, either to less expensive and less unionized rural towns or foreign countries. Even the manufacturers who were committed to staying were ultimately priced out by landlords [3]. This loss of industry coupled with disinvestment from the city and the high crime rates characteristic of late twentieth century New York left the area undesirable to new development [7]. Still, a Polish and Italian population thrived on the Northside, 'residents of the northern waterfront area enjoy shopping on Bedford Avenue, where they can buy produce, fish, meat, eggs and bread from wholesalers' [8] while the Southside is home to many Hispanic-Americans of Puerto Rican descent.

Because of its proximity to Manhattan and cheap rents, Williamsburg attracted artists in the 1980s and 90s. Recently abandoned manufacturing sites became convenient spaces for legal and illegal lofts, studios, galleries and party venues. Gradually cafes and nightclubs were added to the commercial landscape of Williamsburg and by the mid 1990s the area was getting a reputation for bars, music and art [9]. As is well documented for Williamsburg and dozens of similar urban locales, the creative scene cultivated by artists and entrepreneurs attracted increasing numbers of visitors to the neighborhood, creating a demand for more bars, restaurants, and eventually caught the attention of middle-class professionals who could afford, and were charged, higher rents [9, 10].

In 2005 the City Council, under Mayor Michael Bloomberg, approved a rezoning plan for Williamsburg, and the neighboring Greenpoint, that allowed real estate developers to build along the area's waterfront. While the rezoning and private investment that followed did allow for the creation of new public spaces like the East River State Park (which is sometimes closed for expensive, ticketed concerts) and Bushwick Inlet Park (still under construction at the time of writing), it also led to the construction of luxury high rise buildings with amenities that have now welcomed wealthy residents to Williamsburg.

Today the retail landscape has changed from Dorian's 1986 description. You can still buy meat, eggs and bread on Bedford Avenue, but at a much higher price from small boutique delis that also sell organic snacks, frozen dinners and locally produced chocolate for about $\$ 12$ a bar. The Polish butcher shops, Italian bakery and hardware store, once necessities of everyday life for local residents, have been replaced by restaurants, cafes and boutiques. As a twelveyear resident griped, 'the butcher shops aren't here anymore because people don't cook in this neighborhood, everyone eats out.' Many of the local institutions now reflect the preferences of the new wealthier residents.

Although this case study is specific to Williamsburg, the analysis has implications for many other former manufacturing neighborhoods that follow a trajectory of first attracting art, then middle-class consumption and eventually luxury housing and retail $[11,12]$. Thus the implications of public space in a neighborhood that has already experienced 'super-gentrification' is relevant to nearby neighborhoods like Bushwick, Brooklyn [13] and further to Kreuzberg, Berlin [14] or Praga, Warsaw [15]; locations that have gone through only the first or second waves of new residents and uses [16].

\section{BRANDING PUBLIC SPACES}

Public space in a city affords residents the opportunity to interact, socialize, consume and relax beyond the private realm of their apartments. For the purposes of this article there are essentially three types of public space. There are the shops and institutions that we visit on a frequent basis (grocery stores, churches, subway stations, schools); places where we spend leisure time (parks, cafes, restaurants, pedestrian malls); and special-event public spaces like block parties (street closures usually organized by residents) and festivals. This list is not intended to be exhaustive nor exclusive; cafes could be a daily public space if you work in one, and you could spend your leisure time at church. However this categorization as daily, leisure and specialevent public spaces will help to contextualize the relationship between gentrification, branding and public space.

As outlined by Stephen Carr, public spaces - whether daily, leisure, or special-event- should be responsive, democratic and meaningful [17]. Carr argues that they should serve the needs of users, be open to all people and allow individuals to interact and make connections between their private lives and larger context, be it a neighborhood, organization, or so on. The situation becomes problematic when residents do not feel comfortable in their neighborhood's public spaces. This can occur in any of the three types of public spaces.

The daily public spaces of Williamsburg once reflected the working class and immigrant background of long-term residents - for example establishments of necessity like grocers and Laundromats which often had Polish language signage in addition to English [18]. As Williamsburg began to gentrify, existing business owners and new entrepreneurs catered to the changing clientele, and the everyday public spaces of the neighborhood transformed due to private business investment.

Public policy also had an important impact in the shift towards a new Williamsburg. Policy makers are not oblivious to Cybriwsky's point that 'the quality of a city's public spaces has much to do with whether a city, or a particular neighborhood, succeeds or fails as a place to live or do business' [6]; and in recent years city policy has supported public space initiatives to attract residents and visitors. In Williamsburg this was characterized first by a rezoning of the waterfront for condos and public parks, and then with initiatives like Williamsburg Walks. Both tactics relied on private investments to realize a public policy goal, lending cultural capital to the neighborhood [12].

Not all events that go on in gentrified public space are the calculation of business-minded policy makers teamed with real estate developers. Still, community events do send signals about the neighborhood. Local actors - business owners, community organizers and residents - all contribute to the image and identity of a neighborhood [19]. During events like Williamsburg Walks select actors organize 
activities and make the rules. Although Walks was initiated by the Mayor's office, the city does not provide any funding for it. Thus, community groups and local actors that take over the planning must rely on businesses for sponsorship and activities. At public space events, the neighborhood is symbolically owned by the groups and businesses that have a presence on the street, communicating to visitors the aesthetics of luxury and consumption that Williamsburg has become famous for [19].

Alterations in the landscape of everyday public spaces, securitization of leisure spaces, and exclusion at special events are all symptomatic of a gentrified locale. The sum of these parts is a new brand for the neighborhood, communicated through institutions, aesthetics, and events that reflect the values and cultural interests of newcomers and potential visitors (Greenberg 2008). The following account of Williamsburg Walks exemplifies a public space special event that has implications for branding and exclusion in a gentrified neighborhood.

\section{METHODOLOGY}

This study relies on ethnographic data of the Williamsburg Walks street closure from 2008, 2009 and 2010. Each year I attended the summer weekend events taking notes on the activities, observing interactions, documenting the occasion with photography and speaking with participants (residents and visitors of Williamsburg). In addition to the event itself, I sat in at planning meetings for the 2009 and 2010 Walks, as well as the 2011 session, which also served as a summary of the 2010 event.

After each year of Walks, I conducted formal interviews with community organizers, event volunteers, vendors, local artists who participated in 2010's art competition, and storeowners. These interviews, 13 in total, were semistructured and questions were adapted based on issues that came up during the process.

Through communications with Walks planners I obtained digital copies of the end reports for 2008 and 2009. These were internal summary documents prepared by and for the organizers and included post-Walks surveys of stores owners, budgets, logistics and recommendations for the following year. I also accessed the Williamsburg Walks website for a list of sponsors, schedules, and general information about the event.

\section{INITIATING WILLIAMSBURG WALKS}

Williamsburg Walks is a community event that started in the summer of 2008. The project, initially proposed by the New York City Department of Transportation (DOT), was designed to be 'a celebration of the Williamsburg community, centered around a pedestrian-only Bedford Avenue' [20]. The event has taken place each summer since 2008 , occurring on various weekends. The first event shut down the street for four Saturdays, the 2009 edition was extended to six. In 2010 the event was shortened to one weekend in June because of complaints from local business owners. Each time, a few blocks of Bedford Avenue have been transformed from a busy thoroughfare into a venue for picnics, art exhibits, and neighborly interaction.
While the event changed over the three years, the slogan 'rethink your public space' remained constant. With this mantra the organizers (several of them urban planning students from local universities) hoped to communicate that the event should be about community- about neighbors getting out to know one another and using the newfound public space for just about anything non-commercial. Flyers in 2008 reminded residents and visitors that the event was not a street fair 'there will be no funnel cake and no cheap tube socks ${ }^{3} \ldots$ we simply want the community (YOU) to come out and enjoy the public space' [20]. The emphasis for Williamsburg Walks, at least how it has been marketed, is that it is a social experiment- a new way of building community.

DOT began the planning process by contacting Brooklyn's Community Board 1 and the transportation committee chair, Teresa Toro. Teresa had previously worked with business owners a few years prior when the $\mathrm{L}$ train (the main method of public transit in the neighborhood) was out of service for several weekends. Because of her experience with the L, she knew how important it was that the businesses support this new change in vehicle transportation: 'the businesses were really impacted at that time.' It was vital that local business owners understood 'how DOT's idea would differ from a street fair, [there would be] no sidewalk competition for the businesses.' The Williamsburg Walks' website and literature stresses that the event is about members of the community using public space, but the DOT website states 'Local merchants' associations, community groups, and business improvement districts host these Weekend Walks to provide a fun new way to highlight local businesses and cultural institutions' [21].

The role of businesses in Williamsburg Walks is contentious. Some planners claimed that business owners had nothing to do with the concept while others, like Teresa, acknowledged the need for their support. A few owners on Bedford Avenue have fought against the Walks initiative because it hurt their business. Other owners supported the event in hopes that solidarity among local proprietors would facilitate the creation of a Business Improvement District (BID), a formal alliance of business owners who pay fees towards collective interests like increased security or street cleaning. Jason Jeffries, the owner of two Williamsburg stores, included a discussion of the Walks event in a recent grant application for the Northside Merchants Association, a less formal version of a BID. Whatever the capacity business owners played in the production of Williamsburg Walks, their opinions did matter. Complaints about lost profits and competition from street vendors resulted in fewer Walks for 2010 and strict policing of street vendors.

\section{EVOLUTION OF WILLIAMSBURG WALKS 2008- 2010}

\section{Planning and Execution}

The goal of Williamsburg Walks has always been to create a social experiment where people come out and use temporary public space however they would like. This goal

\footnotetext{
${ }^{3}$ The respondent was referring here to inexpensive items that are currently associated with a carnival atmosphere, something the organizers were specifically trying to avoid.
} 
was perhaps only realized for the 2008 edition, after which the event became more programmed and formalized. At noon on July $19^{\text {th }}, 2008$ Williamsburg Walks volunteers set up barricades along seven blocks of Bedford Avenue, from Metropolitan to North $9^{\text {th }}$ streets. Businesses on Bedford Avenue were allowed to use the sidewalks in front of their buildings as extensions of their restaurants or boutiques, and individuals were encouraged to enjoy and creatively use the street. For the most part people simply walked down the street as if it were the sidewalk, but some made use of DOT tables and chairs that had been set up and others sat down with a book or even suntanned. I observed informally at the first of several Walks days. It wasn't that well publicized in my neighborhood and I was confused, as were many others, about the point of the closure. Organizers later acknowledged that promotion was done mainly on the blog for a local community group, Neighbors Allied for Good Growth $^{4}$ (NAG), and by word of mouth. From both my observations at the event and photographs that were later posted on the site, the event looked overwhelmingly homogenous. Most people who participated were young, white Americans. There were few families on the street, and the older Polish and Hispanic residents were almost completely absent.

After the first few Saturdays people began to vend on the street, and despite a large Latina/o community in Williamsburg's Southside, this was really the only Hispanic presence I observed at the 2008 Walks. A few people were selling food and others were having yard sales. Something that the planners did not anticipate was that for many people, amateur entrepreneurialism was how they would use their public space. The merchants complained that the commercial activities taking place on the street were detracting from their businesses, so for 2009 only street vendors who already had licenses to operate on Bedford were allowed to sell during Williamsburg Walks.

The 2008 event was organized by DOT, Community Board 1, and local businesses along with NAG. After the inaugural year the majority of the event was managed by members of NAG, and they held a planning meeting for the 2009 edition in April. There were 9 people at the meeting and the demographics did not fit the broader neighborhood. In attendance were 6 white men, 2 white women, and 1 young black woman. A few of the people in attendance were business owners, and one young man was a writer for ' $\mathrm{L}$ Magazine', a sponsor of Williamsburg Walks.

Based on a survey from the 2008 Walks, there was a perception that people did not really understand the purpose of the street closure. Respondents also mentioned that they would like some activities to be provided [20]. While commerce was a concern, the foci of the 2009 planning meeting was how to bring more programming to the street and to better promote Williamsburg Walks. The individuals present at the meeting decided to have activities catering to 'art, music, community organization, local food [and] family activities' [22].

\footnotetext{
4"NAG" originally stood for "Neighbors Against Garbage" as they formed to protest a waste-management station in Williamsburg, they are now an advocacy group for residents in the neighborhood concerned with tenants rights, water-front zoning issues and other local issues. http://www.nagbrooklyn.org/
}

From my observations the 2009 Walks were better attended. Walking south down Bedford Avenue I noted that many of the restaurants and cafes on the street had extended their services onto the sidewalks and a few of the boutiques placed clothing racks or merchandise outside of their stores. The usual sidewalk vendors set up their wares, and the street was a bit more active than the previous year. Children colored on a giant roll of paper unfurled on one of the streets, there were intermittent performances- some planned, some spontaneous, and several local community groups had information tables on the street. Although illegal vending was prohibited, there were still some people selling food -a woman and her son cooked platanos, or fried Plantains, under a tent while nearby another woman sold horchata, a sweet drink made from rice. Both items are popular among the neighborhood's Latina/o community and again the vendors were among the only Hispanic residents present at the event.

While the 2009 events were more successful in getting people to use public space, there was still an issue of illegal vending which became a very important issue for the 2010 edition of Williamsburg Walks. An internal summary document that the planners put together after the 2009 event stated that 'several people at the wrap up session complained that too many activities were taking place reinforcing the feeling of Bedford Ave as a 'permanent Mardi Gras' and diverting people from shopping' [22]. This indicates that by 2009 the purpose of Williamsburg Walks had shifted from being a 'social experiment' to a local-commerce focused event.

On April $21^{\text {st }}$ the 2010 'Williamsburg Walks Community Brain Storming Session' was held at Teddy's, a restaurant off Bedford Avenue on the Northside. Many more people showed up at this planning meeting, 20 excluding myself. Although the group was larger than the previous year, it was even more homogenous in terms of age and race, but the proportion of men and women was more even. In 2010 the Project for Public Spaces ${ }^{5}$ (PPS) was involved, in addition to NAG. Representatives from PPS gave a presentation on the mission of the year's event: celebrate the neighborhood, relax, shop at local stores, rethink public spaces; but one NAG organizer who helped plan the 2009 Walks stressed that there were no commercial intentions aside from encouraging local businesses.

Illegal vending was a major theme at the meeting. The organizers stated that over the past two years they had realized the importance of enforcing a 'no vending' rule, and that vending would be monitored by the NYPD for 2010. As a result of pressure from local businesses, the organizers decided that having a police presence at the event would be necessary to dissuade illegal activities. They maintained that vendors who were normally on the street would be allowed to continue selling, but no new vendors would be permitted. When one resident asked why it was such a problem, the NAG organizer replied that the extra vendors made it too crowded, and they were trying to promote the established businesses. While promoting local business is one of the

\footnotetext{
${ }^{5}$ Project for Public Spaces is an New York-based organization that assists communities and neighborhood groups in realizing new uses for local public space. http://www.pps.org/.
} 
many benefits of Williamsburg Walks, it was clear from this meeting that it had become a primary goal. As the brainstorming continued, people gave ideas about how to get Walkers to visit stores, including a scavenger hunt or a booth where you could sew your own bag to use while shopping. One PPS representative said he wanted any ideas 'that connect[s] the programming with the merchants.'

The 2010 Williamsburg Walks was the most programmed version to date and the most like a street fair, just shy of the dreaded tube socks and funnel cake. More people were using the space than in years past, likely as a result of the engaging programs. The children's block had an outdoor gymnasium, an art competition was staged throughout the blocks, and a picnic area was set up by the local Community Supported Agriculture ${ }^{6}$ (CSA) group. Williamsburg businesses who do not have a presence on Bedford Avenue were also allowed to use some space in the street. The boutique 'Peachfrog' had a table where they handed out flyers for their shop and 'Jungle,' a garden supply store, set up a green oasis at one end of the event.

Despite not being local to Williamsburg, Brooklyn Brainery and Green Mountain Energy ${ }^{7}$ both had booths set up in the street, the former is based out of downtown Brooklyn but the latter has nothing to do with Brooklyn at all. Although these were not neighborhood institutions, they fit in with the ideals of Williamsburg Walks because they represent leisure activities and alternative energy solutions, respectively. The services offered by these businesses were deemed to have some interest or relevance for Walks attendees and so they were permitted to table at the event. Someone who did not fit in with this image was Charles St. George. Charles was selling jewelry at the corner of a side street. His NYC permit was clearly displayed but he was located on a cross street instead of directly on Bedford Avenue. I was surprised at this since he was clearly an authorized vendor, and at the planning meeting organizers confirmed that the usual vendors would be permitted. He showed me a letter he received from Williamsburg Walks planners stating that there would be no street vending allowed and police action would be taken if he set up his booth on Bedford Avenue. Charles is a usual fixture on Bedford, and has been for a few years-longer than some of the newer boutiques and bars. He said he appreciated what Williamsburg Walks did for the community, but he found it unfair that he was suddenly not allowed to sell in his regular spot. Groups like Brooklyn Brainery and Green Mountain, although not local, were encouraged to take up space on Bedford Avenue because these organizations reflect the concerns and hobbies of Williamsburg's wealthier residents. Charles' 'street boutique' does not fit with these tastes and so he was explicitly excluded from the event.

Although the 2010 event was more successful in attracting families it was still not representative of the diverse community. Williamsburg Walks has its own website where it hosts pictures and videos of previous Walks, FAQs,

\footnotetext{
${ }^{6} \mathrm{~A}$ CSA is a cooperative model in which individuals join a group and purchase produce directly from a farm or collection of farms.

${ }^{7}$ Brooklyn Brainery is a creative DIY 'school' where people sign up to take classes, topics ranging from cooking or crafts to informational, if esoteric, lectures. Green Mountain is a renewable energy company that provides solutions to businesses and private consumers.
}

and a map of the planned activities. Blogs like 'free Williamsburg' and 'Greenpointers' also advertise the event, but the ads that were posted in public spaces in 2008 and 2009 were deliberately vague offering slogans like 'Walk Bedford' or 'Do you suffer from don't-speak-to-yourneighbor-itis?' These signs lacked any details beyond the date and time of the event. In 2010 there were no physical flyers, only an Internet presence, for many residents this meant not knowing about the event until it was taking place. When I asked an organizer from 2008 about the low rate of participation from Polish and Puerto Rican businesses and residents, he replied that the flyers given to merchants were not translated into Polish and Spanish early enough for distribution. The lack of outreach to the Polish and Hispanic communities in the neighborhood inhibits their participation. Without targeted advertising via translated and publicly posted flyers, some residents have no prior knowledge of the event. They may come to Bedford Avenue during Walks, but from my observations this only results in confusion.

I met Lilian and Stan, a Ukrainian and Polish couple, sitting on chairs on the sidewalk at the end of the event on Sunday in 2010. I asked if they had participated in any way 'There's nothing here for us,' Lilian replied. Gladys, a Puerto Rican woman, was studying the activities map with her husband and daughter when I approached them. It was around $5 \mathrm{pm}$ on Saturday and the event was packing up for the day. I asked if they had participated in Williamsburg Walks and Gladys replied that they had just wandered over because they were wondering why the street was closed.

The lack of outreach to long-time residents coupled with the increasing focus on consumption reflects broader tensions in Williamsburg. Williamsburg Walks is a special event which occurs in an everyday public space-a commercial street. While the event is taking place, the space becomes a medium to highlight the new brand of Williamsburg as a leisure destination for shopping and dining. There are countless articles highlighting the neighborhood's consumption opportunities like bars, restaurant and boutiques. Williamsburg has appeared in print from The New York Times to GQ, a men's fashion magazine, as well as travel guidebooks for New York. The name is now synonymous with food, art, and gentrification, and the programming at Williamsburg Walks reflects this narrative. The planning of Walks supports the Williamsburg brand by including consumption activities while implicitly excluding less wealthy residents or unfashionable vendors from the neighborhood's visible spaces-an issue that is not only a problem for Williamsburg, but also many gentrifying locales.

\section{CONCLUSIONS}

Williamsburg Walks certainly provides many benefits to the neighborhood. Having a car free street gives everyone (theoretically) an opportunity to enjoy public space. The children's block at the 2009 and 2010 Walks gave diverse guardians the opportunity to socialize. Residents and visitors were able to use the street to share food, play games, and make crafts-undoubtedly leading to a stronger, if temporary, sense of 'community' among participants. However there are serious problems with the execution and goals of Williamsburg Walks. The event has become a 
strategy in the branding of Williamsburg, leading to the privileged inclusion of some and the exclusion of others. Although the initial concept of the event seems benign, a critical exploration of the processes leading up to Williamsburg Walks exposes it as a microcosm of gentrification in the neighborhood.

Certain groups of long-term residents were noticeably absent from the event, specifically Hispanic and Polish residents who are often less wealthy than newcomers. Older adults were also rarely present despite the fact that they can often be seen socializing in other public spaces, like stoops on side streets and a Polish bakery steps away from Bedford. This is due to two factors: a lack of both outreach and programming. When the event is advertised in public the signage is ambiguous, as if it is promoting one of the neighborhood's secret parties instead of an event that will take up the street for several days. When long-term residents do visit Bedford Avenue during Walks, they find a lack of relevant programming. Much of what is planned for Williamsburg Walks revolves around experimental art and luxury shopping, concepts that may not appeal to these groups. One exception is the children's block, which is popular among many neighborhood families and the most diverse section of the Walks, indicating that if there is something of broader interest, various groups of residents will participate.

Less wealthy residents, members of the Hispanic and Polish communities, and older adults are often left on the periphery of the event, if present at all. These groups are not targeted in the advertisement of Walks because their presence is not necessary to promote the neighborhood. Inexpensive ethnic consumables like pierogi and arepas attract foodies to the neighborhood, but the everyday aspects and aesthetics of the working-class culture-butchers, bodegas, and multi-lingual signage-are disappearing in favor of upscale restaurants and boutiques.

The original purpose of Walks was to utilize temporary public space, but at the 2010 event nearly every activity (aside from viewing the art competition) served as advertising for local businesses. Returning to Carr's requirements that public space be responsive, democratic and meaningful, we can see where events like Williamsburg Walks fall short [17]. With a focus on consumption, less wealthy residents were not engaged in the activities - the event was not responsive to their needs and desires of public space. The event is not democratic in outreach or programming. In 2010, and later in 2011 and 2012, the event was not advertised in Williamsburg's public spaces, only on the Internet. Certain businesses - like the Children's Gym and Jungle plant nursery - were allowed to sell or advertise on the street. This was a luxury that was not afforded to the book vendors and the Mexican food stands that are a daily fixture on Bedford Avenue and certainly contribute to the everyday public space of the neighborhood. Because the event does not encourage programming to attract the neighborhood's elderly, ethnic or working-class residents, it is not a meaningful space for all.
For residents like Lilian, Stan and Gladys, there was no way for them to meaningfully connect their private lives to the public environment [17]. Events like Walks have the capacity to bring diverse neighbors into contact with one another, but will only exacerbate existing tensions if they continue to promote upper class luxury and consumption.

\section{CONFLICT OF INTEREST}

The authors confirm that this article content has no conflict of interest.

\section{ACKNOWLEDGEMENTS}

Declared none.

\section{REFERENCES}

[1] Marcuse P. The Enclave, the citadel, and the ghetto: what has changed in the post-Fordist U.S. city. Urban Affairs Rev 1997; 33(2): 228-64

[2] Patch J. The embedded landscape of gentrification. Visual Stud 2004; 19: 169-86.

[3] Curran W. Gentrification and the nature of work: exploring the links in Williamsburg, Brooklyn. Environ Plan A 2004; 36: 124358.

[4] Zukin S, Trujillo V, Frase $\mathrm{P}$, et al. New retail capital and neighborhood change: boutiques and gentrification in New York City. City Commun 2009; 8(1): 47-64.

[5] Bourdieu P. Distinction: a social critique of the judgment of taste. trans. Richard Nice. Cambridge, MA: Harvard University Press 1984.

[6] Cybriwsky R. Changing patterns of urban public space: observations and assessments from the Tokyo and New York metropolitan areas. Cities 1999; 16(4): 223-31.

[7] Greenberg M. Branding New York: how a city in crisis was sold to the world. New York: Routledge 2008.

[8] Dorian D. If you're thinking of living in Williamsburg. The New York Times 1986 June 15.

[9] Zukin S. Naked city: the death and life of authentic urban places. New York: Oxford University Press 2010.

[10] Smith N. Uneven development : nature, capital, and the production of space. New York: Blackwell 1984.

[11] Ley D. Artists, aestheticisation and the field of gentrification. Urban Stud 2003; 40(12): 2527-44.

[12] Cameron S, Coaffee J. Art, gentrification and regeneration: from artist as pioneer to public arts. Eur J Housing Policy 2005; 5(1): 3958.

[13] Zukin S, Braslow L. The life cycle of New York's creative districts: Reflections on the unanticipated consequences of unplanned cultural zones. City, Cult Society 2011; 2(3): 131-40.

[14] Bader I, Bialluch M. Gentrification and the creative class in BerlinKreuzberg. In: Porter L, Shaw K. Whose urban renaissance? an international comparison of urban regeneration strategies. London: Routledge 2009.

[15] Lorens P. Trends and problems of contemporary urbanization processes in Poland. In: Altrock U, Guntner S, Huning S, and Peters D. Eds. Spatial planning and urban development in the new EU member states: from adjustment to reinvention. Aldershot, England: Ashgate 2006.

[16] Lees L. Super-gentrification: the case of Brooklyn Heights, New York City. Urban Stud 2003; 40(12): 2487-509.

[17] Carr S, Francis M, Rivlin L, Stone A. Public Space. New York: Cambridge University Press 1992.

[18] Martucci S. Williamsburg walks: public space and community events in a gentrified neighborhood. In: Desena J, Shortell T, Eds. The world in Brooklyn: gentrification, immigration, and ethnic politics in a global city. Lanham, Maryland: Lexington Books 2012.

[19] Deener A. Commerce as the structure and symbol of neighborhood life: reshaping the meaning of community in Venice, California. City Commun 2007; 6(4): 291-312. 
[20] Colvin C, Feingold D, Sweet A. Williamsburg walks end report. Blenderbox 2008.

[21] Department of Transportation. New York Weekend Walks. New York: The City of New York; 2012; 2010 December 5. Available from: http://www.nyc.gov/html/dot/weekendwalks/html/home/hom e.shtml

[22] Williamsburg Walks 2009-2010 Report. accessed via private correspondence 2010 November 29.

Received: April 19, 2012

Revised: October 22, 2012

Accepted: January 9, 2013

(C) Sara Martucci; Licensee Bentham Open.

This is an open access article licensed under the terms of the Creative Commons Attribution Non-Commercial License (http://creativecommons.org/licenses/by$\mathrm{nc} / 3.0 /$ ) which permits unrestricted, non-commercial use, distribution and reproduction in any medium, provided the work is properly cited. 